\title{
Predictors of duloxetine response in patients with oxaliplatin-induced painful chemotherapy-induced peripheral neuropathy (CIPN): a secondary analysis of randomised controlled trial - CALGB/alliance 170601
}

E.M.L. SMITH, PHD, APN-BC, AOCN $\circledast$, ASSOCIATE PROFESSOR AND DIRECTOR, PhD program, University of Michigan School of Nursing, Ann Arbor, MI, H. PANG, PHD, ADJUNCt Assistant Professor, Alliance Statistics and Data Center, Duke University, Durham, NC, Department of Biostatistics and Bioinformatics, Duke University, Durham, NC, and School of Public Health, Li Ka Shing Faculty of Medicine, Hong Kong SAR, China, C. YE, MS, biostatistician, Alliance Statistics and Data Center, Duke University, Durham, NC, C. CIRRINCIONE, ms, Biostatistician, Alliance Statistics and Data Center, Duke University, Durham, NC, and Department of Biostatistics and Bioinformatics, Duke University, Durham, NC, S. FLEISHMAN, MD, DIRECTOR, Cancer Supportive Services program, Continuum Cancer Centers of New York: Beth Israel and St. Luke's-Roosevelt, New York, NY, E.D. PASKETT, PHD, PROFEsSOR, The Ohio State University Comprehensive Cancer Center, College of Medicine, Department of Internal Medicine, Columbus, OH, T. AHLES, PHD, PSYCHOLOGIST, Memorial Sloan-Kettering Cancer Center, New York, NY, L.R. BRESSLER, PHARMD, Clinical associate professor emerita, University of Illinois College of Pharmacy (Emeritus Faculty), Chicago, IL, N. LE-LINDQWISTER, MD, oncologist/hematologist, Illinois Oncology Research Association, Peoria, IL, C.E. FADUL, mD, Professor, Norris Cotton Cancer Center Dartmouth-Hitchcock Medical Center, Lebanon, NH, C. LOPRINZI, MD, Professor, Mayo Clinic, Rochester, Rochester, MN, C.L. SHAPIRO, MD, PrOFESSOR, Mount Sinai Medical Center, Division of Hematology/Medical Oncology: Tisch Cancer Institute, New York, NY, USA; for the ALLIANCE FOR CLINICAL TRIALS IN ONCOLOGY

SMITH E.M.L., PANG H., YE C., CIRRINCIONE C., FLEISHMAN S., PASKETT E.D., AHLES T., BRESSLER L.R., LE-LINDQWISTER N., FADUL C.E., LOPRINZI C. \& SHAPIRO C.L.; for the Alliance for Clinical Trials in Oncology (2017) European Journal of Cancer Care 26, e12421, doi: 10.1111/ecc.12421

Predictors of duloxetine response in patients with oxaliplatin-induced painful chemotherapy-induced peripheral neuropathy (CIPN): a secondary analysis of randomised controlled trial - CALGB/Alliance 170601

Duloxetine is an effective treatment for oxaliplatin-induced painful chemotherapy-induced peripheral neuropathy (CIPN). However, predictors of duloxetine response have not been adequately explored. The objective of this secondary and exploratory analysis was to identify predictors of duloxetine response in patients with painful oxaliplatin-induced CIPN. Patients $(N=106)$ with oxaliplatin-induced painful CIPN were randomised to receive duloxetine or placebo. Eligible patients had chronic CIPN pain and an average neuropathic pain score $\geq 4 / 10$. Duloxetine/placebo dose was $30 \mathrm{mg} / \mathrm{day}$ for 7 days, then $60 \mathrm{mg} /$ day for 4 weeks. The Brief Pain Inventory-Short Form and the EORTC QLQ-C30 were used to assess pain and quality of life, respectively. Univariate and multiple logistic regression analyses were performed

Correspondence address: Ellen M. Lavoie Smith, University of Michigan School of Nursing, 400 North Ingalls, Ann Arbor, MI 48109, USA (e-mail: ellenls@med.umich.edu).

Accepted 22 October 2015

DOI: $10.1111 /$ ecc. 12421

European Journal of Cancer Care, 2017, 26, e12421, DOI: 10.1111/ecc.12421

(c) 2015 John Wiley \& Sons Ltd 
to identify demographic, physiologic and psychological predictors of duloxetine response. Higher baseline emotional functioning predicted duloxetine response $(\geq 30 \%$ reduction in pain; OR 4.036 ; $95 \%$ CI 0.999 $16.308 ; p=0.050$ ). Based on the results from a multiple logistic regression using patient data from both the duloxetine and placebo treatment arms, duloxetine-treated patients with high emotional functioning are more likely to experience pain reduction $(p=0.026)$. In patients with painful, oxaliplatin-induced CIPN, emotional functioning may also predict duloxetine response. ClinicalTrials.gov, Identifier NCT00489411

Keywords: Duloxetine, chemotherapy-induced peripheral neuropathy, pain, oxaliplatin.

\section{INTRODUCTION}

Chemotherapy is a mainstay of cancer treatment that is received by millions of cancer survivors. Chemotherapyinduced peripheral neuropathy (CIPN) is a common side effect of neurotoxic chemotherapeutic agents such as oxaliplatin, and many others (Argyriou et al. 2010; Beijers et al. 2014). Numbness and tingling in the hands and feet are the most common symptoms and CIPN becomes chronically painful in approximately $20-42 \%$ of cases (Dworkin 2002; Cavenagh et al. 2006; Hausheer et al. 2006; Taylor 2006; Argyriou et al. 2008a, Windebank \& Grisold 2008; Smith et al. 2010; Sonneveld \& Jongen 2010; Kautio et al. 2011; Geber et al. 2013). Consequently, CIPN can evolve into a chronic pain syndrome that impairs function and quality of life (QOL) (Calhoun et al. 2003; Cella et al. 2003; Almadrones et al. 2004; Bakitas 2007; Bruner et al. 2007; Kiser et al. 2010; Tofthagen 2010; Plotti et al. 2011; Mols et al. 2014).

Unfortunately, evidence-based, effective interventions for painful CIPN are rare. Duloxetine, a serotonin-norepinephrine reuptake inhibitor, is the only recommended treatment for painful oxaliplatin-induced CIPN (Hershman et al. 2014). Duloxetine works by increasing the amount of key pain-inhibiting neurotransmitters, serotonin and norepinephrine, within the central nervous system (Bymaster et al. 2003). Although the original randomised, placebo-controlled trial conducted by the Cancer and Leukemia Group B (CALGB) provides strong evidence of duloxetine efficacy, just $33 \%$ of the duloxetine-treated patients experienced a moderate pain reduction $(\geq 30 \%)$, and even fewer $(21 \%)$ experienced a substantial decrease in pain $(\geq 50 \%)$ (Smith et al. 2013). Moreover, duloxetine was ineffective in $41 \%$ of the study participants (Smith et al. 2013). Since duloxetine was not completely effective, nor did it work for everyone, identifying predictors of duloxetine response is a priority area for future research. More specifically, if we know why duloxetine works, for whom and in what circumstances, a personalised approach can be used to prescribe duloxetine to those most likely to benefit.

A clue regarding one possible predictor of duloxetine response can be found in the original report of the CALGB study (Smith et al. 2013). More specifically, the results of an exploratory responder analysis suggest that patients with oxaliplatin-induced painful CIPN are more likely to experience a benefit from duloxetine than patients with paclitaxel-induced CIPN (Smith et al. 2013). This finding suggests that duloxetine's mechanism of action may be uniquely tied to very specific mechanisms of chemotherapy-induced neurotoxicity. Although the precise mechanism of chronic oxaliplatininduced CIPN is still unknown, studies have shown that oxaliplatin accumulates in the dorsal root ganglion where it causes nerve cell apoptosis (Cavaletti et al. 2001; Renn et al. 2011). In addition, an oxaliplatin metabolite, oxalate, chelates calcium and impairs calcium-sensitive sodium-dependent ion channel function, leading to peripheral nerve hyper-excitability /Grolleau et al. 2001; Wilson et al. 2002; Krishnan et al. 2005; Benoit et al. 2006; Park et al. 2009; Beijers et al. 2014). In contrast, taxanes disrupt microtubules, causing CIPN by subsequent demyelination and impairment of axonal transport (Persohn et al. 2005; Argyriou et al. 2008b; Park et al. 2011). Other taxane-induced nerve injury mechanisms include macrophage activation in peripheral nerves and dorsal root ganglia, microglial activation and down-regulation of glutamate transporters in the spinal cord, and damaged mitochondria in A- and Cfibres (Cata et al. 2006; Flatters \& Bennett 2006; Peters et al. 2007; Argyriou et al. 2008b, 2012; Jin et al. 2008). We found no other published studies exploring a differential response to duloxetine based on the causative chemotherapeutic agent; more research in this area is needed.

The chronic pain literature provides additional clues about other possible predictors of duloxetine response. Widespread body pain, emotional distress (e.g., anxiety, 
depression), fatigue, impaired cognition, and sleep disturbance are centrally mediated symptoms that co-occur in a variety of chronic pain conditions and predict pain severity (Clauw \& Chrousos 1997; Fukuda et al. 1997, 1998; Clark et al. 2000; Bair et al. 2003; Giesecke et al. 2003; Gore et al. 2005, 2006; Heitkemper \& Jarrett 2005; Postma et al. 2005; Castillo et al. 2006; Zelman et al. 2006; Bakitas 2007; Geisser et al. 2007, 2008a,b; Allen et al. 2008; Clemens et al. 2008; Fishbain et al. 2008; Roy-Byrne et al. 2008; Zhang \& Jordan 2008; Warren et al. 2009; Desaulniers 2011; Tofthagen 2011; Geber et al. 2013). Individuals with painful CIPN also experience similar centrally mediated symptoms (Nail 2011; Tofthagen et al. 2013). Since co-occurring symptoms can make chronic pain worse, patients with painful CIPN who also experience co-occurring symptoms may be less responsive to analgesic interventions like duloxetine. Accordingly, this paper reports the results of secondary and exploratory analyses (using data from the CALGB trial) that were performed to determine whether the European Organisation for the Research and Treatment of Cancer Quality of Life Questionnaire (EORTC QLQ-C30) subscale scores for emotional and cognitive functioning, fatigue and insomnia would predict duloxetine response in the CALGB patient cohort that experienced the best effect - those with oxaliplatin-induced CIPN. The primary hypothesis is that baseline severity of co-occurring symptoms common to chronic pain disorders - emotional distress, impaired cognition, fatigue, and insomnia - will predict duloxetine efficacy in patients with chronic, painful oxaliplatin-induced CIPN.

\section{METHODS}

\section{Sample and setting}

Between April 2008 and March 2011, CALGB 170601 enrolled 231 participants $\geq 25$ years of age from 105 academic and community sites throughout the United States. All patients provided signed Institutional Review Boardapproved informed consent. Patient eligibility has been previously described (Smith et al. 2013). Briefly, eligible participants reported sensory neuropathy >grade 1 using the National Institutes of Health Common Terminology Criteria for Adverse Events (CTCAE) v. 3.0 grading scale, an average CIPN-related neuropathic pain score $\geq 4$ on a 0 10 scale using the Brief Pain Inventory-Short Form (BPISF) item 5, and persistent pain at least 3 months after completion of paclitaxel or oxaliplatin treatment. Patients could not have received other types of neurotoxic chemotherapy drugs (e.g. vinca alkaloids, bortezomib, thalidomide), and those with neuropathy due to other comorbid conditions were not eligible. Concurrent use of other antidepressants, anticonvulsants, high-dose vitamin supplements or drugs known to influence serotonin levels (e.g. tramadol) was not allowed.

\section{Procedure}

The research methods used in CALGB 170601 have been previously described (Smith et al. 2013). Eligible participants were randomised to receive either duloxetine $60 \mathrm{mg}$ or placebo. Stratified, random assignment to treatment groups was determined by the CALGB/Alliance Statistics and Data Center based on the neurotoxic drug received (taxane versus platinum) and CIPN risk [high risk (those with diabetes mellitus) versus low risk]. All patients and personnel were blinded to treatment assignment.

Duloxetine/placebo was started at $30 \mathrm{mg}$ daily for the first week. Beginning on day 8,4 weeks of full dose (60 mg) duloxetine/placebo treatment began. Starting at week 6, participants underwent a 2-week washout period and then crossed over to the other treatment arm.

A clinical research associate telephoned each patient weekly to ask them to rate CIPN pain severity using the BPI-SF. The BPI-SF is a well-validated 15-item instrument that includes items quantifying average, worst, least and immediate pain severity using a $0-10$ numeric rating scale (Cleeland et al. 1994; Cleeland 2009). The BPI-SF has been tested in culturally and linguistically diverse populations with various types of painful disorders, providing evidence of internal consistency and test-retest reliability, and construct, structural, concurrent and discriminant validity (Cleeland 2009). BPI-SF item \#5, which quantifies average pain severity using a $0-10$ scale, was used to assess duloxetine response.

Participants also completed the EORTC QLQ-C30 on day 1 of weeks 1, 6, 8 and 13. The EORTC QLQ-C30 is comprised of several core components applicable to all cancer patients (Aaronson et al. 1993). Its 30 items are grouped into subscales assessing global health status and QOL (2); physical (5), role (2), emotional (4), cognitive (2) and social (2) functioning; fatigue (3); nausea and vomiting (2); and pain (2). The questionnaire assesses six additional items: dyspnoea, insomnia, appetite loss, constipation, diarrhoea and financial difficulties. Respondents rate their global health status and QOL from 1 (very poor) to 7 (excellent). The degree to which respondents are experiencing other problems is rated on a 4-point Likert scale, ranging from 'Not at All' to 'Very Much'. For the current analysis, we focused on specific subscales known to be associated with chronic pain: emotional and cognitive functioning, fatigue, pain and insomnia. The emotional subscale items 
quantify whether the respondent worries, or feels tense, irritable or depressed. Items in the cognitive function subscale assess concentration and memory. The fatigue subscale asks about weakness, the need for rest and feeling tired. Two pain subscale items ask if respondents have had pain and about pain's influence on performance of daily activities. The insomnia question quantifies whether the respondent has had trouble sleeping. Cronbach's alpha coefficients for the global health status, emotional and cognitive functioning, fatigue and pain subscales range from 0.73 to 0.89 (Aaronson et al. 1993). Test-retest reliability correlations range from 0.70 to 0.90 for all subscales (Hjermstad et al. 1995). Satisfactory construct validity has been previously demonstrated (Aaronson et al. 1993).

\section{Analyses}

Given the exploratory nature of the analyses, an a priori power analysis was not conducted. However, to minimise the risk of false discovery, all analyses were conducted using data obtained only from oxaliplatin-treated patients in the initial treatment period (weeks 1-5), because the subgroup analysis for the paclitaxel cohort did not yield significant differences in pain reduction. A post hoc power analysis revealed that there would be $60 \%$ power (two-sided inflated alpha of 0.10 ) to detect predictors of duloxetine response if $25 \%$ of patients responded in the below-median group versus $53 \%$ of those in the above-median group. Statistical analyses were performed by the Alliance Statistics and Data Center, using SAS 9.3 (Cary, $\mathrm{NC}$ ) on a database locked in April 2012.

We focused on exploring whether EORTC QLQ-30 subscale scores quantifying known predictors of chronic pain severity (emotional function, impaired cognition, fatigue and insomnia) might predict duloxetine response, defined as a $\geq 30 \%$ improvement (Dworkin et al. 2009) in pain severity during the initial treatment period based on the pain score obtained from BPI-SF item \# 5. Differences in demographic variables between duloxetine and placebo arms were compared using $t$-tests for continuous variables and chi-squared tests or Fisher's exact tests for categorical variables (Fleiss 1981; Altman 1991). Descriptive statistics [medians, frequencies, 95\% confidence intervals (CI)] were calculated to describe the incidence of duloxetine response by chemotherapy agent. Young/old age and low/ high EORTC QLQ-30 subscale scores were defined based on medians of the distributions. Changes in EORTC subscale scores were summarised using means and standard deviations (SDs), and compared by general linear mod- elling adjusted for baseline score and neuropathy risk (presence/absence of diabetes). High/low subscale scores were defined as being either above or below the medians.

Univariate and multiple logistic regression analyses were performed to identify predictors for duloxetine response. To test for an interaction effect of emotional functioning and treatment arm, we constructed a multiple logistic regression model (controlling for baseline CTCAE neuropathy grade) using patient data from the duloxetine and placebo treatment arms. Odds ratios for the selected baseline EORTC QLQ-30 subscales scores were calculated using the scores between 0 and 100 and divided by $33^{1} / 3$. This rescales the scores back to the original range for ease of interpretation. The odds ratio for global health status was calculated based on the actual scores. The proportion of missing data was $\leq 4 \%$ for the primary outcome; therefore, we took a complete case analysis approach. To test for a treatment group effect on the change in EORTC QLQ-C30 subscale scores during the initial treatment period, we used analysis of covariance, each stratified by neurotoxic agent and comorbid risk (presence/absence of diabetes), and including the baseline measure of the corresponding subscale scores.

\section{RESULTS}

\section{Patient characteristics}

Patients' demographic characteristics (Table 1) were derived using data obtained only from the patients with oxaliplatin-associated painful CIPN $(n=106$; duloxetine $n=49$; placebo $n=57)$. The oxaliplatin sample was primarily men (64.2\%) and Caucasian (85.9\%). Most patients had good performance status $(85.9 \%)$ and had undergone chemotherapy treatment for a stage I-III $(79.2 \%)$ gastrointestinal malignancy $(98.1 \%)$. The mean age was 59.7 years, and the mean baseline pain score was 5.8 out of 10 . With the exception of the baseline neuropathy grade (duloxetine group mean grade $=2.35$, SD 0.52); placebo group mean grade $=2.26$, SD 0.41), no statistically significant differences in demographic characteristics between the duloxetine- and placebo-treated groups were found.

\section{Incidence of duloxetine response}

Table 2 illustrates the incidence of duloxetine responders in the oxaliplatin-treated cohort. To avoid the risk of false discovery due to multiple testing, statistical tests were not performed using these data. Nevertheless, the findings support the hypothesis that patients with more severe symptoms are less likely to benefit from 
Table 1. Demographics characteristics

\begin{tabular}{|c|c|c|c|c|}
\hline \multirow[b]{2}{*}{ Characteristics } & \multicolumn{3}{|c|}{ No. of participants $(\%)$} & \multirow[b]{2}{*}{$p$} \\
\hline & $\begin{array}{l}\text { Duloxetine } \\
(n=49)\end{array}$ & $\begin{array}{l}\text { Placebo } \\
(n=57)\end{array}$ & $\begin{array}{l}\text { Total } \\
(n=106)\end{array}$ & \\
\hline \multicolumn{5}{|l|}{ Age (years) } \\
\hline $30-39$ & $0(0)$ & $1(1.8)$ & $1(0.9)$ & \multirow[t]{6}{*}{$0.882^{\star}$} \\
\hline $40-49$ & $6(12.2)$ & $11(19.3)$ & $17(16.0)$ & \\
\hline $50-59$ & $22(44.9)$ & $20(35.1)$ & $42(39.6)$ & \\
\hline $60-69$ & $16(32.7)$ & $15(26.3)$ & $31(29.3)$ & \\
\hline$\geq 70$ & $5(10.2)$ & 10 (17.5) & $15(14.2)$ & \\
\hline Mean (SD) & $59.86(9.52)$ & $59.56(10.97)$ & $59.70(10.28)$ & \\
\hline \multicolumn{5}{|l|}{ Sex } \\
\hline Men & $28(57.1)$ & $40(70.2)$ & $68(64.2)$ & \multirow[t]{2}{*}{0.163} \\
\hline Women & $21(42.9)$ & $17(29.8)$ & $38(35.8)$ & \\
\hline \multicolumn{5}{|l|}{ Race } \\
\hline White & $43(87.8)$ & $48(84.2)$ & $91(85.9)$ & \multirow[t]{4}{*}{0.547} \\
\hline Black & $5(10.2)$ & $4(7.0)$ & $9(8.5)$ & \\
\hline Other & $1(2.0)$ & $3(5.3)$ & $4(3.8)$ & \\
\hline Not reported & $0(0)$ & $2(3.5)$ & $2(1.9)$ & \\
\hline \multicolumn{5}{|c|}{ High risk of chemotherapy-induced peripheral neuropathy } \\
\hline No & $22(44.9)$ & $26(45.6)$ & $48(45.3)$ & \multirow[t]{2}{*}{0.941} \\
\hline Yes & $27(55.1)$ & $31(54.4)$ & $58(54.7)$ & \\
\hline \multicolumn{5}{|l|}{ Primary disease } \\
\hline GI & $48(98.0)$ & $56(98.2)$ & $104(98.1)$ & \multirow[t]{2}{*}{1.000} \\
\hline Other & $1(2.0)$ & $1(1.8)$ & $2(1.9)$ & \\
\hline \multicolumn{5}{|l|}{ Disease stage } \\
\hline Early I-II & $10(20.4)$ & $15(26.3)$ & $25(23.6)$ & \multirow[t]{3}{*}{0.604} \\
\hline III & $27(55.1)$ & $32(56.1)$ & $59(55.7)$ & \\
\hline Metastatic & $12(24.5)$ & $10(17.5)$ & $22(20.8)$ & \\
\hline \multicolumn{5}{|c|}{ Performance status } \\
\hline 0 & $26(53.1)$ & $29(50.9)$ & $55(51.9)$ & \multirow[t]{3}{*}{1.000} \\
\hline 1 & $22(44.9)$ & $26(45.6)$ & $48(45.3)$ & \\
\hline $2+$ & $1(2.0)$ & $2(3.5)$ & $3(2.8)$ & \\
\hline \multicolumn{5}{|c|}{ Sensory neuropathy gradet } \\
\hline Mean (SD) & $2.35(0.52)$ & $2.26(0.41)$ & $2.25(0.47)$ & $0.040^{\star}$ \\
\hline \multicolumn{5}{|c|}{ Baseline pain score } \\
\hline$<4$ & $1(2.0)$ & $0(0)$ & $1(0.9)$ & \multirow[t]{5}{*}{$0.189^{\star}$} \\
\hline $4-5$ & $19(38.8)$ & $32(56.1)$ & $51(48.1)$ & \\
\hline $6-7$ & $19(38.8)$ & $18(31.6)$ & $37(34.9)$ & \\
\hline $8-10$ & $10(20.4)$ & $7(12.3)$ & $17(16.0)$ & \\
\hline Mean (SD) & $6.00(1.70)$ & $5.58(1.58)$ & $5.77(1.64)$ & \\
\hline
\end{tabular}

^Tested as a continuous variable.

tBased on National Cancer Institute Common Terminology for Adverse Events (NCI-CTCAE) Sensory Neuropathy Grade.

duloxetine. The biggest differences in duloxetine response were seen when examining the percentage of responders experiencing high versus low emotional functioning, fatigue and pain. Approximately $28 \%$ more patients with high versus low emotional functioning responded to duloxetine. Furthermore, when compared to patients with higher levels of fatigue and pain, more patients with low scores, $25.5 \%$ and $23.8 \%$ respectively, responded to duloxetine.

\section{EORTC QLQ-C30 subscale scores}

Table 3 presents the change from baseline to 6-week EORTC QLQ-C30 subscale scores in duloxetine- and pla- cebo-treated patients. After adjusting for the baseline pain score and CIPN risk (presence/absence of diabetes), duloxetine-treated patients reported a greater improvement in global health $(p=0.005)$, cognitive function $(p=0.021)$ and pain $(p=0.020)$ than did placebo-treated patients.

\section{Predictors of duloxetine response}

The results of a univariate logistic regression, presented in Table 4, suggest that patients with better baseline emotional functioning scores were four times more likely to respond to duloxetine treatment (OR 4.036; $95 \%$ CI 0.999$16.308 ; p=0.050$ ). Baseline cognition, fatigue and insomnia scores did not predict duloxetine response. Based on the results from a multiple logistic regression using patient data from both the duloxetine and placebo treatment arms, the interaction $p$-value of emotional functioning and treatment arm (duloxetine versus placebo) was 0.026, suggesting that duloxetine-treated patients with oxaliplatininduced CIPN pain and high emotional functioning are more likely to obtain $\mathrm{a} \geq 30 \%$ reduction in pain.

\section{DISCUSSION}

Based on the results of a recently published systematic review of randomised controlled trials testing CIPN interventions, duloxetine is the only drug recommended for the treatment of chronic CIPN pain (Hershman et al. 2014). As expected, duloxetine is not universally effective (Smith et al. 2013), and the reasons for its selective efficacy are unknown. The results of these secondary and exploratory analyses suggest that patients with better baseline emotional health (feeling less worried, tense, irritated, depressed) are four times more likely to respond to duloxetine, suggesting that those whose pain is part of a larger symptom cluster may benefit the least. These findings are consistent with the results of many studies showing that anxiety predicts pain perception (Theunissen et al. 2012; Schreiber et al. 2013; Bruce et al. 2014; Miaskowski et al. 2014). One such study reported that patients who were more anxious were more likely to have painful versus non-painful CIPN (Geber et al. 2013). Their findings reinforce what is known about the relationship between anxiety and pain and suggest that the patients in our study with high emotional functioning scores responded better to duloxetine because they were less worried and tense - emotions/feelings which are similar to anxiety. The implication for clinical practice is that perhaps emotionally distressed/anxious patients should be offered anxiety-relieving interventions alongside duloxetine. 
Table 2. Incidence of responders *

\begin{tabular}{|c|c|c|c|c|c|}
\hline \multirow[b]{2}{*}{ Variable } & \multirow[b]{2}{*}{ Median } & \multicolumn{2}{|l|}{ Duloxetine $(n=49)$} & \multicolumn{2}{|l|}{ Placebo $(n=57)$} \\
\hline & & \# Responders/Total $n$ & $\%$ Responders $(95 \% \mathrm{CI})$ & \# Responders/Total $n$ & \% Responders (95\% CI) \\
\hline \multicolumn{6}{|l|}{ Age } \\
\hline Older & & $13 / 26$ & $50.0(29.9-70.1)$ & $4 / 27$ & $14.8(4.2-33.7)$ \\
\hline \multicolumn{6}{|l|}{ Gender } \\
\hline Male & & $11 / 28$ & $39.3(21.5-59.4)$ & $6 / 40$ & $15.0(5.7-29.8)$ \\
\hline Female & & $10 / 21$ & $47.6(25.7-70.2)$ & $2 / 17$ & $11.8(1.5-36.4)$ \\
\hline Low & 66.6 & $9 / 26$ & $34.6(17.2-55.7)$ & $4 / 23$ & $17.4(5.0-38.8)$ \\
\hline High & & $12 / 22$ & $54.6(32.2-75.6)$ & $4 / 34$ & $11.8(3.3-27.5)$ \\
\hline \multicolumn{6}{|c|}{ Emotional functioning } \\
\hline Low & 75.0 & $4 / 16$ & $25.0(7.2-52.4)$ & $5 / 25$ & $20.0(6.8-40.7)$ \\
\hline High & & $17 / 32$ & $53.1(34.7-70.9)$ & $3 / 32$ & $9.4(2.0-25.0)$ \\
\hline \multicolumn{6}{|c|}{ Cognitive functioning } \\
\hline \multicolumn{6}{|l|}{ Pain } \\
\hline Low & 50.0 & $12 / 21$ & $57.1(34.0-78.2)$ & $2 / 19$ & $10.5(1.3-33.1)$ \\
\hline High & & $9 / 27$ & $33.3(16.5-54.0)$ & $6 / 38$ & $15.8(6.0-31.3)$ \\
\hline \multicolumn{6}{|l|}{ Insomnia } \\
\hline Low & 33.3 & $4 / 11$ & $36.4(10.9-69.2)$ & $2 / 14$ & $14.3(1.8-42.8)$ \\
\hline High & & $17 / 37$ & $46.0(29.5-63.1)$ & $6 / 43$ & $14.0(5.3-27.9)$ \\
\hline
\end{tabular}

${ }^{\star}$ Responders $=\geq 30 \%$ improvement in pain score during initial treatment period based on the pain score from BPI-SF item \# 5. EORTC QLQ-30 subscale scores are baseline measurements obtained at week 1 of the initial treatment period. Young/old age and low/high scores are defined based on medians of the distributions.

Table 3. Change from baseline to 6-week EORTC QLQ-C30 subscale scores

\begin{tabular}{|c|c|c|c|c|c|c|c|}
\hline \multirow[b]{2}{*}{ Variable } & \multicolumn{3}{|c|}{$\begin{array}{l}\text { Change in mean } \\
\text { score following } \\
\text { duloxetine } \\
\text { treatment }\end{array}$} & \multicolumn{3}{|c|}{$\begin{array}{l}\text { Change in mean } \\
\text { score following } \\
\text { placebo } \\
\text { treatment }\end{array}$} & \multirow[b]{2}{*}{$p$} \\
\hline & Mean & SD & $N$ & Mean & SD & $N$ & \\
\hline $\begin{array}{l}\text { Global health } \\
\text { status }\end{array}$ & 8.1 & 23.1 & 44 & -3.8 & 18.0 & 50 & $0.005^{\star}$ \\
\hline $\begin{array}{l}\text { Emotional } \\
\text { functioning }\end{array}$ & 6.8 & 16.2 & 44 & 3.7 & 17.3 & 50 & 0.074 \\
\hline $\begin{array}{l}\text { Cognitive } \\
\text { functioning }\end{array}$ & 7.6 & 18.1 & 44 & 0.67 & 16.8 & 50 & $0.021^{*}$ \\
\hline Fatigue & -3.6 & 23.7 & 43 & -3.3 & 16.5 & 50 & 0.725 \\
\hline Pain & -9.8 & 24.2 & 44 & -4.1 & 16.5 & 49 & $0.020^{*}$ \\
\hline Insomnia & -3.0 & 21.3 & 44 & 0.0 & 26.1 & 50 & 0.547 \\
\hline
\end{tabular}

Change scores were calculated by subtracting baseline from week 6 subscale scores obtained only in the sample of patients who provided a week 6 score.

${ }^{\star}$ Greater improvement in duloxetine-treated patients than placebo-treated patients.

We found no other published studies designed to explore whether a patient profile predicts the likelihood of clinically meaningful duloxetine-induced pain relief in patients with CIPN. However, two studies of duloxetine response in patients with other chronic pain conditions (migraine headache, fibromyalgia) who received similar doses suggest that patients with more severe baseline anxiety and depression were more likely to respond (Taylor et al. 2007; Marangell et al. 2011). In the current study, those with better emotional functioning were more likely to achieve at least a $30 \%$ reduction in pain. Our findings may vary from those of other published chronic pain studies due to differences in underlying pain and stress mechanisms in patients with non-malignant pain versus cancer treatment-related pain. In addition, these discordant results may stem from variations in measurement approaches. For this secondary data analysis, emotional functioning was quantified using a four-item EORTC QLQ-30 subscale that assessed the degree to which the patient felt worried, tense, irritated or depressed. Because the EORTC QLQ-30 subscale quantifies a different emotional phenotype than instruments designed to diagnose mood disorders (anxiety and depression), the current findings are not directly comparable with other chronic pain studies.

An alternative explanation for the difference in duloxetine response rates may be related to differences in patients' underlying pain mechanisms. For example, some patients may have pain caused by multiple/mixed mechanisms, both peripheral nociceptive and central neuropathic. This idea is supported by Geber et al. (2013), 60\% 
Table 4. Predictors of duloxetine response

\begin{tabular}{|c|c|c|c|c|c|}
\hline \multirow[b]{2}{*}{ Variable } & \multicolumn{2}{|c|}{$\begin{array}{l}\text { Baseline } \\
\text { EORTC } \\
\text { QLQ-30 } \\
\text { score }\end{array}$} & \multicolumn{3}{|c|}{$\begin{array}{l}\text { Univariate logistic } \\
\text { regression }\end{array}$} \\
\hline & Mean & SD & $\begin{array}{l}\text { Odds } \\
\text { ratio }^{*}\end{array}$ & $95 \% \mathrm{CI}$ & $p$ \\
\hline \multicolumn{6}{|l|}{ Duloxetine arm } \\
\hline $\begin{array}{l}\text { Global health } \\
\text { status }\end{array}$ & 62.0 & 22.1 & 1.015 & $0.99-1.04$ & 0.310 \\
\hline $\begin{array}{l}\text { Emotional } \\
\text { functioning }\end{array}$ & 78.3 & 15.4 & 4.036 & $0.99-16.31$ & 0.050 \\
\hline $\begin{array}{l}\text { Cognitive } \\
\text { functioning }\end{array}$ & 80.6 & 17.0 & 1.286 & $0.41-4.01$ & 0.665 \\
\hline Fatigue & 35.7 & 23.6 & 0.526 & $0.22-1.29$ & 0.159 \\
\hline Pain & 45.8 & 28.2 & 0.749 & $0.38-1.50$ & 0.412 \\
\hline Insomnia & 38.2 & 29.2 & 1.398 & $0.71-2.74$ & 0.328 \\
\hline \multicolumn{6}{|l|}{ Placebo arm } \\
\hline $\begin{array}{l}\text { Global health } \\
\text { status }\end{array}$ & 62.6 & 20.1 & 0.980 & $0.94-1.02$ & 0.266 \\
\hline Emotional & 72.1 & 23.7 & 0.577 & $0.21-1.55$ & 0.276 \\
\hline Cognitive & 77.5 & 19.5 & 0.779 & $0.22-2.73$ & 0.696 \\
\hline Fatigue & 33.9 & 22.9 & 1.879 & $0.67-5.26$ & 0.230 \\
\hline Pain & 52.3 & 23.9 & 1.308 & $0.46-3.73$ & 0.615 \\
\hline Insomnia & 39.2 & 31.6 & 0.935 & $0.42-2.09$ & 0.870 \\
\hline
\end{tabular}

Duloxetine response $=\geq 30 \%$ improvement in pain score during initial treatment period based on the pain score from BPI-SF item \#5.

* Odds ratios for EORTC QLQ-30 function and symptom scores are calculated based on the scores divided by $33^{1} / 3$; odds ratio for global health status is calculated based on the scores. 'Based on the results from a multiple logistic regression using patient data from both treatment arms (duloxetine and placebo) and adjusting for baseline neuropathy severity, the interaction $p$ value of emotional functioning and treatment arm was 0.026 .

of whose study subjects with painful CIPN also reported pain with musculoskeletal (nociceptive) characteristics. Perhaps non-responding CALGB 170601 participants experienced more nociceptive pain due to musculoskeletal symptoms, multiple surgeries, or radiation therapy. Since nociceptive/peripheral pain is less responsive to centrally acting drugs like duloxetine, a higher incidence of mixed pain in non-responding patients might partially explain duloxetine's selective efficacy.

Given these considerations, the cause of duloxetine's selective effect may lie within the central nervous system. Although not well understood, mechanisms involved in the development of chronic neuropathic pain include abnormal neuron receptors and ion channel function, increased production and release of pain-facilitating neurotransmitters, and faulty central nervous system-mediated pain excitatory and inhibitory systems (Baron et al. 2010). A study conducted in patients with painful diabetic neuropathy provides preliminary evidence that inefficient central nervous system-mediated pain inhibition - mediated by serotonin and norepinephrine - predicts better dulox- etine response (Yarnitsky et al. 2012). This finding suggests that duloxetine may be less effective for patients with normally functioning pain inhibitory systems.

This study has several limitations. First, although the results suggest that better emotional health was the only hypothesised variable that predicts duloxetine response, the sample size of responders may have been too small to detect statistically significant associations between baseline cognitive functioning, fatigue, and insomnia subscale scores and duloxetine response. In addition, we hypothesised that the EORTC QLQ-C30 subscale scores for factors known to be associated with chronic pain severity in other populations - emotional and cognitive functioning, fatigue and insomnia - would be most closely associated with duloxetine response. However, other well-known predictors of chronic pain severity were not assessed, such as previous trauma exposure (e.g., sexual/physical abuse, physical trauma, deployment to war) (Campbell \& Lewandowski 1997; Golding 1999; Coker et al. 2000; Baccini et al. 2003; Meltzer-Brody et al. 2007; Humphreys et al. 2010; Barry et al. 2011; Raphael \& Widom 2011) and the tendency to catastrophise about pain (believing that pain is profoundly awful) (Sullivan et al. 2001; Edwards et al. 2006, 2011; Campbell \& Edwards 2009). EORTC QLQC30 subscale scores, used to quantify the predictor variables, may be less sensitive than other validated measures of psychological and physical symptoms. Last, although patients in the duloxetine group were taking fewer concomitant analgesics than the placebo-treated patients at baseline and at study completion, analgesic dosage in the oxaliplatin group could have increased over the initial treatment period, accounting for improvements in pain. These possible changes in concomitant analgesic dosage were not quantified (Smith et al. 2013).

The findings of this secondary data analysis suggest that patients with better baseline emotional functioning may be more likely to benefit from duloxetine. The next step is to conduct adequately powered follow-up studies to confirm these findings, and to identify other predictors of duloxetine response that might be amenable to complementary interventions. Patients with greater emotional distress and other sources of pain (muscle/joint pain associated with endocrine therapy for breast cancer) may require additional pharmacologic and/or non-pharmacologic interventions combined with duloxetine in order to achieve clinically significant improvements in pain. Thus, uncovering a patient phenotype associated with duloxetine efficacy could help clinicians make more informed decisions about who should receive the drug, and which patients may benefit from multi-modality treatments. 


\section{FUNDING}

This study was supported by the NCI Division of Cancer Prevention, the Alliance Statistics and Data Center grant and the Alliance Chairman's Grant (Alliance/CALGB CA31946). Drug and placebo were supplied by Eli Lilly and Company.

\section{ROLE OF THE SPONSOR}

The NCI and Eli Lilly and Company each reviewed and approved the study concept via the usual peer-review process. Minor suggestions were made by each group regarding aspects of the study design. The NCI provided funding for data management and statistical analysis. Neither the
NCI Division of Cancer Prevention nor Eli Lilly and Company had a role in data collection or management, analysis, interpretation of the data, or with manuscript preparation, review or approval.

\section{ACKNOWLEDGEMENTS}

We thank the study participants and the research staff at all participating sites. Special thanks are extended to the CALGB Oncology Nursing Committee; Richard Schilsky, M.D.; Xiaofei Wang, PhD; John Taylor, MA; Brandelyn Pitcher, MS; Sara Jasinski, BA; Chetay Knox, BS; Paul B. Gilman, MD; Celia M. Bridges, BA, BSN, RN; and Asa B. Smith.

\section{REFERENCES}

Aaronson N.K., Ahmedzai S., Bergman B., Bullinger M., Cull A., Duez N.J., Filiberti A., Flechtner H., Fleishman S.B. \& de Haes J.C. (1993) The European Organization for Research and Treatment of Cancer QLQ-C30: a quality-of-life instrument for use in international clinical trials in oncology. Journal of the National Cancer Institute 85, 365-376.

Allen K.D., Renner J.B., Devellis B., Helmick C.G. \& Jordan J.M. (2008) Osteoarthritis and sleep: the Johnston County Osteoarthritis Project. Journal of Rheumatology 35, 1102-1107.

Almadrones L., McGuire D.B., Walczak J.R., Florio C.M. \& Tian C. (2004) Psychometric evaluation of two scales assessing functional status and peripheral neuropathy associated with chemotherapy for ovarian cancer: a gynecologic oncology group study. Oncology Nursing Forum Online 31, 615-623.

Altman D.G. (1991) Practical Statistics for Medical Research translated by Anonymous Chapman \& Hall, London, UK.

Argyriou A.A., Iconomou G. \& Kalofonos H.P. (2008a) Bortezomib-induced peripheral neuropathy in multiple myeloma: a comprehensive review of the literature. Blood 112, 1593-1599.

Argyriou A.A., Koltzenburg M., Polychronopoulos P., Papapetropoulos S. \& Kalofonos H.P. (2008b) Peripheral nerve damage associated with administration of taxanes in patients with cancer. Critical Reviews in Oncology-Hematology 66, 218-228.

Argyriou A.A., Zolota V., Kyriakopoulou O. \& Kalofonos H.P. (2010) Toxic peripheral neuropathy associated with commonly used chemotherapeutic agents. Journal of BUON 15, 435-446.

Argyriou A.A., Bruna J., Marmiroli P. \& Cavaletti G. (2012) Chemotherapyinduced peripheral neurotoxicity (CIPN): an update. Critical Reviews in Oncology-Hematology 82, 51-77.

Baccini F., Pallotta N., Calabrese E., Pezzotti P. \& Corazziari E. (2003) Prevalence of sexual and physical abuse and its relationship with symptom manifestations in patients with chronic organic and functional gastrointestinal disorders. Digestive and Liver Disease 35, 256-261.

Bair M.J., Robinson R.L., Katon W. \& Kroenke K. (2003) Depression and pain comorbidity: a literature review. Archives of Internal Medicine 163, 2433-2445.

Bakitas M.A. (2007) Background noise: the experience of chemotherapy-induced peripheral neuropathy. Nursing Research 56, 323-331.

Baron R., Binder A. \& Wasner G. (2010) Neuropathic pain: diagnosis, pathophysiological mechanisms, and treatment. Lancet Neurology 9, 807819.

Barry D.T., Beitel M., Cutter C.J., Garnet B., Joshi D., Rosenblum A. \& Schottenfeld R.S. (2011) Exploring relations among traumatic, posttraumatic, and physical pain experiences in methadone-maintained patients. Journal of Pain 12, 22-28.

Beijers A.J., Mols F. \& Vreugdenhil G. (2014) A systematic review on chronic oxaliplatin-induced peripheral neuropathy and the relation with oxaliplatin administration. Supportive Care in Cancer 22, 1999-2007.

Benoit E., Brienza S. \& Dubois J.M. (2006) Oxaliplatin, an anticancer agent that affects both $\mathrm{Na}+$ and $\mathrm{K}+$ channels in frog peripheral myelinated axons. General Physiology and Biophysics 25, 263-276.

Bruce J., Thornton A.J., Powell R., Johnston M., Wells M., Heys S.D., Thompson A.M., Smith W.C., Chambers W.A. \& Scott N.W. (2014) Psychological, surgical, and sociodemographic predictors of pain outcomes after breast cancer surgery: a population-based cohort study. Pain 155, 232-243.

Bruner D.W., Barsevick A., Tian C., Randall M., Mannel R., Cohn D.E., Sorosky J. \& Spirtos N.M. (2007) Randomized trial results of quality of life comparing whole abdominal irradiation and combination chemotherapy in advanced endometrial carcinoma: a gynecologic oncology group study. Quality of Life Research 16, 89-100.

Bymaster F.P., Beedle E.E., Findlay J., Gallagher P.T., Krushinski J.H., Mitchell S., Robertson D.W., Thompson D.C., Wallace L. \& Wong D.T. (2003) Duloxetine (Cymbalta), a dual inhibitor of serotonin and norepinephrine reuptake. Bioorganic and Medicinal Chemistry Letters 13, 4477-4480.

Calhoun E.A., Welshman E.E., Chang C.H., Lurain J.R., Fishman D.A., Hunt T.L. \& Cella D. (2003) Psychometric evaluation of the Functional Assessment of Cancer Therapy/Gynecologic Oncology GroupNeurotoxicity (Fact/GOG-Ntx) questionnaire for patients receiving systemic chemotherapy. International Journal of Gynecological Cancer 13, 741-748.

Campbell C.M. \& Edwards R.R. (2009) Mind-body interactions in pain: the neurophysiology of anxious and 
catastrophic pain-related thoughts. Translational Research 153, 97-101.

Campbell J.C. \& Lewandowski L.A. (1997) Mental and physical health effects of intimate partner violence on women and children. Psychiatric Clinics of North America 20, 353-374.

Castillo R., MacKenzie E., Wegener S. \& Bosse M. (2006) Prevalence of chronic pain seven years following limb threatening lower extremity trauma. Pain 124, 321.

Cata J.P., Weng H.R., Chen J.H. \& Dougherty P.M. (2006) Altered discharges of spinal wide dynamic range neurons and down-regulation of glutamate transporter expression in rats with paclitaxel-induced hyperalgesia. Neuroscience 138, 329-338.

Cavaletti G., Tredici G., Petruccioli M.G., Dondè E., Tredici P., Marmiroli P., Minoia C., Ronchi A., Bayssas M. \& Griffon Etienne G. (2001) Effects of different schedules of oxaliplatin treatment on the peripheral nervous system of the rat. European Journal of Cancer 37, 2457-2463.

Cavenagh J., Good P. \& Ravenscroft P. (2006) Neuropathic pain: are we out of the woods yet? Internal Medicine Journal 36, 251-255.

Cella D., Peterman A., Hudgens S., Webster K. \& Socinski M.A. (2003) Measuring the side effects of taxane therapy in oncology: the functional assesment of cancer therapy-taxane (FACT-taxane). Cancer 98, 822-831.

Clark M.R., Heinberg L.J., Haythornthwaite J.A., QuatranoPiacentini A.L., Pappagallo M. \& Raja S.N. (2000) Psychiatric symptoms and distress differ between patients with postherpetic neuralgia and peripheral vestibular disease. Journal of Psychosomatic Research 48, 51.

Clauw D.J. \& Chrousos G.P. (1997) Chronic pain and fatigue syndromes: overlapping clinical and neuroendocrine features and potential pathogenic mechanisms. NeuroImmunoModulation 4, 134.

Cleeland C.S. (2009) The Brief Pain Inventory User Guide. Available at: http://www.mdanderson.org/educationand-research/departments-programs-andlabs/departments-and-divisions/ symptom-research/symptomassessment-tools/BPI_UserGuide.pdf (accessed July 28, 2009).

Cleeland C.S., Gonin R., Hatfield A.K., Edmonson J.H., Blum R.H., Stewart J.A. \& Pandya K.J. (1994) Pain and its treatment in outpatients with metastatic cancer. New England Journal of Medicine, 330, 592-596 (33 ref).
Clemens J.Q., Meenan R., O'Keeffe Rosetti M.C., Kimes T. \& Calhoun E. (2008) Case-control study of medical comorbidities in women with interstitial cystitis. The Journal of Urology 179, 2222-2225.

Coker A.L., Smith P.H., Bethea L., King M.R. \& McKeown R.E. (2000) Physical health consequences of physical and psychological intimate partner violence. Archives of Family Medicine 9, 451457.

Desaulniers G.A. (2011) Chemotherapy induced peripheral neuropathy and subjective sleep quality in non-small cell lung cancer. Oncology Nursing Forum 38, A56.

Dworkin R.H. (2002) An overview of neuropathic pain: syndromes, symptoms, signs, and several mechanisms. Clinical Journal of Pain 18, 343-349.

Dworkin R.H., Turk D.C., McDermott M.P., Peirce-Sandner S., Burke L.B., Cowan P., Farrar J.T., Hertz S., Raja S.N., Rappaport B.A., Rauschkolb C. \& Sampaio C. (2009) Interpreting the clinical importance of group differences in chronic pain clinical trials: IMMPACT recommendations. Pain 146, 238-244.

Edwards R.R., Bingham C.O. 3rd, Bathon J. \& Haythornthwaite J.A. (2006) Catastrophizing and pain in arthritis, fibromyalgia, and other rheumatic diseases. Arthritis and Rheumatism 55, 325-332.

Edwards R.R., Calahan C., Mensing G., Smith M. \& Haythornthwaite J.A. (2011) Pain, catastrophizing, and depression in the rheumatic diseases. Nature Reviews Rheumatology 7, 216224.

Fishbain D.A., Detke M.J., Wernicke J., Chappell A.S. \& Kajdasz D.K. (2008) The relationship between antidepressant and analgesic responses: findings from six placebo-controlled trials assessing the efficacy of duloxetine in patients with major depressive disorder. Current Medical Research and Opinion 24, 3105-3115.

Flatters S.J.L. \& Bennett G. (2006) Studies of peripheral sensory nerves in paclitaxel-induced painful peripheral neuropathy: evidence for mitochondrial dysfunction. Pain 122, 245.

Fleiss J.L. (1981) Statistical Methods for Rates and Proportions, 2nd edn, translated by Anonymous. John Wiley \& Sons, New York, NY, USA.

Fukuda K., Dobbins J.G., Wilson L.J., Dunn R.A., Wilcox K. \& Smallwood D. (1997) An epidemiologic study of fatigue with relevance for the chronic fatigue syndrome. Journal of Psychiatric Research 31, 19.

Fukuda K., Nisenbaum R., Stewart G., Thompson W.W., Robin L., Washko R.M., Noah D.L., Barrett D.H., Randall B., Herwaldt B.L., Mawle A.C. \& Reeves W.C. (1998) Chronic multisymptom illness affecting Air Force veterans of the Gulf War. JAMA 280, 981.

Geber C., Breimhorst M., Burbach B., Egenolf C., Baier B., Fechir M., Koerber J., Treede R.D., Vogt T. \& Birklein F. (2013) Pain in chemotherapy-induced neuropathy-more than neuropathic? Pain 154, 2877-2887.

Geisser M.E., Gracely R.H., Giesecke T., Petzke F.W., Williams D.A. \& Clauw D.J. (2007) The association between experimental and clinical pain measures among persons with fibromyalgia and chronic fatigue syndrome. European Journal of Pain 11, 202-207.

Geisser M.E., Glass J.M., Rajcevska L.D., Clauw D.J., Williams D.A., Kileny P.R. \& Gracely R.H. (2008a) A psychophysical study of auditory and pressure sensitivity in patients with fibromyalgia and healthy controls. Journal of Pain 9, 417-422.

Geisser M.E., Strader Donnell C., Petzke F., Gracely R.H., Clauw D.J. \& Williams D.A. (2008b) Comorbid somatic symptoms and functional status in patients with fibromyalgia and chronic fatigue syndrome: sensory amplification as a common mechanism. Psychosomatics 49, 235-242.

Giesecke T., Williams D., Harris R., Cupps T., Tian X., Tian T., Gracely R. \& Clauw D. (2003) Subgrouping of fibromyalgia patients on the basis of pressure-pain thresholds and psychological factors. Arthritis and Rheumatism 48, 2916.

Golding J.M. (1999) Sexual assault history and headache: five general population studies. Journal of Nervous and Mental Disease 187, 624-629.

Gore M., Brandenburg N., Dukes E., Hoffman D., Tai K. \& Stacey B. (2005) Pain severity in diabetic peripheral neuropathy is associated with patient functioning, symptom levels of anxiety and depression, and sleep. Journal of Pain and Symptom Management 30, 374.

Gore M., Brandenburg N., Hoffman D., Tai K. \& Stacey B. (2006) Burden of illness in painful diabetic peripheral neuropathy: the patients' perspectives. The Journal of Pain 7, 892.

Grolleau F., Gamelin L., Boisdron-Celle M., Lapied B., Pelhate M. \& Gamelin E. (2001) A possible explanation for a neurotoxic effect of the anticancer agent oxaliplatin on neuronal voltage-gated 
sodium channels. Journal of Neurophysiology 85, 2293-2297.

Hausheer F.H., Schilsky R.L., Bain S., Berghorn E.J. \& Lieberman F. (2006) Diagnosis, management, and evaluation of chemotherapy-induced peripheral neuropathy. Seminars in Oncology 33, 15-49.

Heitkemper M. \& Jarrett M. (2005) Overlapping conditions in women with irritable bowel syndrome. Urologic Nursing, 25, 25-30 Quiz 31.

Hershman D.L., Lacchetti C., Dworkin R.H., Lavoie Smith E.M., Bleeker J., Cavaletti G., Chauhan C., Gavin P., Lavino A., Lustberg M.B., Paice J., Schneider B., Smith M.L., Smith T., Terstriep S., Wagner-Johnston N., Bak K. \& Loprinzi C.L. (2014) Prevention and management of chemotherapyinduced peripheral neuropathy in survivors of adult cancers: American Society of Clinical Oncology Clinical Practice Guideline. Journal of Clinical Oncology 32, 1941-1967

Hjermstad M.J., Fossa S.D., Bjordal K. \& Kaasa S. (1995) Test/retest study of the European Organization for Research and Treatment of Cancer Core Quality-of-Life Questionnaire. Journal of Clinical Oncology 13, 1249-1254.

Humphreys J., Cooper B.A. \& Miaskowski C. (2010) Differences in depression, posttraumatic stress disorder, and lifetime trauma exposure in formerly abused women with mild versus moderate to severe chronic pain. Journal of Interpersonal Violence 25, 23162338.

Jin H.W., Flatters S.J., Xiao W.H., Mulhern H.L. \& Bennett G.J. (2008) Prevention of paclitaxel-evoked painful peripheral neuropathy by acetyl-L-carnitine: effects on axonal mitochondria, sensory nerve fiber terminal arbors, and cutaneous Langerhans cells. Experimental Neurology 210, 229-237.

Kautio A.L., Haanpaa M., Kautiainen H., Kalso E. \& Saarto T. (2011) Burden of chemotherapy-induced neuropathy - a cross-sectional study. Supportive Care in Cancer 19, 1991-1996.

Kiser D.W., Greer T.B., Wilmoth M.C., Dmochowski J. \& Naumann R.W. (2010) Peripheral neuropathy in patients with gynecologic cancer receiving chemotherapy: patient reports and provider assessments. Oncology Nursing Forum 37, 758-764.

Krishnan A.V., Goldstein D., Friedlander M. \& Kiernan M.C. (2005) Oxaliplatininduced neurotoxicity and the development of neuropathy. Muscle and Nerve 32, 51-60.
Marangell L.B., Clauw D.J., Choy E., Wang F., Shoemaker S., Bradley L., Mease P. \& Wohlreich M.M. (2011) Comparative pain and mood effects in patients with comorbid fibromyalgia and major depressive disorder: secondary analyses of four pooled randomized controlled trials of duloxetine. Pain 152, 31-37.

Meltzer-Brody S., Leserman J., Zolnoun D., Steege J., Green E. \& Teich A. (2007) Trauma and posttraumatic stress disorder in women with chronic pelvic pain. Obstetrics and Gynecology 109, 902-908.

Miaskowski C., Paul S.M., Cooper B., West C., Levine J.D., Elboim C., Hamolsky D., Abrams G., Luce J., Dhruva A., Langford D.J., Merriman J.D., Kober K., Baggott C., Leutwyler H. \& Aouizerat B.E. (2014) Identification of patient subgroups and risk factors for persistent arm/shoulder pain following breast cancer surgery. European Journal of Oncology Nursing 18, 242-253.

Mols F., Beijers T., Vreugdenhil G. \& van de Poll-Franse L. (2014) Chemotherapyinduced peripheral neuropathy and its association with quality of life: a systematic review. Supportive Care in Cancer 22, 2261-2269.

Nail L. (2011) Symptoms and physical function following treatment among people with chemotherapy-induced peripheral neuropathy. Oncology Nursing Forum 38, A48-A49.

Park S.B., Lin C.S., Krishnan A.V., Goldstein D., Friedlander M.L. \& Kiernan M.C. (2009) Oxaliplatininduced neurotoxicity: changes in axonal excitability precede development of neuropathy. Brain 132, 2712-2723.

Park S.B., Lin C.S., Krishnan A.V., Friedlander M.L., Lewis C.R. \& Kiernan M.C. (2011) Early, progressive, and sustained dysfunction of sensory axons underlies paclitaxel-induced neuropathy. Muscle and Nerve 43, 367-374.

Persohn E., Canta A., Schoepfer S., Traebert M., Mueller L., Gilardini A., Galbiati S., Nicolini G., Scuteri A., Lanzani F., Giussani G. \& Cavaletti G. (2005) Morphological and morphometric analysis of paclitaxel and docetaxelinduced peripheral neuropathy in rats. European Journal of Cancer 41, 14601466.

Peters C.M., Jimenez-Andrade J.M., Jonas B.M., Sevcik M.A., Koewler N.J., Ghilardi J.R., Wong G.Y. \& Mantyh P.W. (2007) Intravenous paclitaxel administration in the rat induces a peripheral sensory neuropathy characterized by macrophage infiltration and injury to sensory neurons and their supporting cells. Neurology 203, 42-54.

Plotti F., Sansone M., Di Donato V., Antonelli E., Altavilla T., Angioli R. \& Panici P.B. (2011) Quality of life and sexual function after type C2/type III radical hysterectomy for locally advanced cervical cancer: a prospective study. The Journal of Sexual Medicine 8, 894-904.

Postma T.J., Aaronson N.K., Heimans J.J., Muller M.J., Hildebrand J.G., Delattre J.Y., Hoang-Xuan K., Lanteri-Minet M., Grant R., Huddart R., Moynihan C., Maher J. \& Lucey R. and EORTC Quality of Life Group (2005) The development of an EORTC quality of life questionnaire to assess chemotherapy-induced peripheral neuropathy: the QLQ-CIPN20. European Journal of Cancer 41, 11351139.

Raphael K.G. \& Widom C.S. (2011) Posttraumatic stress disorder moderates the relation between documented childhood victimization and pain 30 years later. Pain 152, 163-169.

Renn C.L., Carozzi V.A., Rhee P., Gallop D., Dorsey S.G. \& Cavaletti G. (2011) Multimodal assessment of painful peripheral neuropathy induced by chronic oxaliplatin-based chemotherapy in mice. Molecular Pain 7, 29.

Roy-Byrne P.P., Davidson K.W., Kessler R.C., Asmundson G.J., Goodwin R.D., Kubzansky L., Lydiard R.B., Massie M.J., Katon W., Laden S.K. \& Stein M.B. (2008) Anxiety disorders and comorbid medical illness. General Hospital Psychiatry 30, 208-225.

Schreiber K.L., Martel M.O., Shnol H., Shaffer J.R., Greco C., Viray N., Taylor L.N., McLaughlin M., Brufsky A., Ahrendt G., Bovbjerg D., Edwards R.R. \& Belfer I. (2013) Persistent pain in postmastectomy patients: comparison of psychophysical, medical, surgical, and psychosocial characteristics between patients with and without pain. Pain 154, 660-668.

Smith E.M., Cohen J.A., Pett M.A. \& Beck S.L. (2010) The reliability and validity of a modified total neuropathy scorereduced and neuropathic pain severity items when used to measure chemotherapy-induced peripheral neuropathy in patients receiving taxanes and platinums. Cancer Nursing 33, 173183.

Smith E.M., Pang H., Cirrincione C., Fleishman S., Paskett E.D., Ahles T., Bressler L.R., Fadul C.E., Knox C., LeLindqwister N., Gilman P.B. \& Shapiro C.L. and Alliance for Clinical Trials in Oncology (2013) Effect of duloxetine on pain, function, and quality of life among 
patients with chemotherapy-induced painful peripheral neuropathy: a randomized clinical trial. IAMA 309, 1359-1367.

Sonneveld P. \& Jongen J.L. (2010) Dealing with neuropathy in plasmacell dyscrasias. Hematology 2010, 423430.

Sullivan M.J., Thorn B., Haythornthwaite J.A., Keefe F., Martin M., Bradley L.A. \& Lefebvre J.C. (2001) Theoretical perspectives on the relation between catastrophizing and pain. Clinical Journal of Pain 17, 52-64.

Taylor R.S. (2006) Epidemiology of refractory neuropathic pain. Pain Practice 6, 22-26.

Taylor A.P., Adelman J.U. \& Freeman M.C. (2007) Efficacy of duloxetine as a migraine preventive medication: possible predictors of response in a retrospective chart review. Headache 47, 1200-1203.

Theunissen M., Peters M.L., Bruce J., Gramke H.F. \& Marcus M.A. (2012) Preoperative anxiety and catastrophizing: a systematic review and meta-analysis of the association with chronic postsurgical pain. The Clinical Journal of Pain 28, 819-841

Tofthagen C. (2010) Patient perceptions associated with chemotherapy-induced peripheral neuropathy. Clinical Journal of Oncology Nursing 14, E22.

Tofthagen C. (2011) Relationships between chemotherapy-induced peripheral neuropathy, depressive symptoms, and sleep quality in colorectal cancer patients previously treated with oxaliplatin. Oncology Nursing Forum 38, A55-A56.

Tofthagen C., Donovan K.A., Morgan M.A., Shibata D. \& Yeh Y. (2013) Oxaliplatin-induced peripheral neuropathy's effects on health-related quality of life of colorectal cancer survivors. Supportive Care in Cancer 21, 3307-3313.

Warren J.W., Howard F.M., Cross R.K., Good J.L., Weissman M.M., Wesselmann U., Langenberg P., Greenberg P. \& Clauw D.J. (2009) Antecedent nonbladder syndromes in case-control study of interstitial cystitis/painful bladder syndrome. Urology 73, 52-57.

Wilson R.H., Lehky T., Thomas R.R., Quinn M.G., Floeter M.K. \& Grem J.L. (2002) Acute oxaliplatin-induced peripheral nerve hyperexcitability. Journal of Clinical Oncology 20, 17671774.

Windebank A.J. \& Grisold W. (2008) Chemotherapy-induced neuropathy. Journal of the Peripheral Nervous System 13, 27-46.

Yarnitsky D., Granot M., NahmanAverbuch H., Khamaisi M. \& Granovsky Y. (2012) Conditioned pain modulation predicts duloxetine efficacy in painful diabetic neuropathy. Pain 153, 1193-1198.

Zelman D.C., Brandenburg N.A. \& Gore M. (2006) Sleep impairment in patients with painful diabetic peripheral neuropathy. Clinical Journal of Pain 22, 681-685.

Zhang Y. \& Jordan J. (2008) Epidemiology of osteoarthritis. Rheumatic Diseases Clinics of North America 34, 515. 